\title{
Clinical appearance of oral lesions in bronchial asthma patients using inhalation drug
}

\author{
Audrey Amber Vieri ${ }^{1 *}$, Rosiliwati Wihardja ${ }^{2}$, Tenny Setiani Dewi ${ }^{1}$ \\ ${ }^{1}$ Department of Oral Medicine, Faculty of Dentistry Universitas Padjadjaran, Indonesia \\ ${ }^{2}$ Department of Oral Biology, Faculty of Dentistry Universitas Padjadjaran, Indonesia
}

\begin{abstract}
Introduction: Inhalation therapy has become the first-line treatment for bronchial asthma patients. Studies have proved that not all of the inhaled drugs reach the target organ, but mostly are deposited in the mouth and cause local immunosuppressant and decrease saliva secretion. These conditions are closely linked to some adverse effects in the mouth. The purpose of this study was to describe the clinical appearance of oral lesion in bronchial asthma patients using inhalation drugs. Methods: This study was descriptive and conducted on 30 bronchial asthma patients that have been using inhalation drug for at least one year, free of other systemic diseases, not using denture and orthodontic appliances. Oral mucosa was examined, and any oral lesion was recorded. Results: The most number of oral lesions found in patients through clinical examinations were plaque (73.3\%), followed by a fissure (36.7\%), atrophy (30\%), and the least oral lesions found were pigmentation (3.3\%), bullae (3.3\%), and petechiae (3.3\%). The lesions found in patients using inhalation drugs in a range of up to 10 years were found more varyingly. Conclusion: Plaque, fissure, atrophy, pigmentation, bullae, and petechiae are oral lesions that are clinically found in bronchial asthma patients using inhalation drugs.
\end{abstract}

Keywords: Bronchial asthma, inhalation drug, oral lesion.

p-ISSN: 1979-0201; e-ISSN: 2549-6212; Available from: http://jurnal.unpad.ac.id/pjd/article/view/27472

DOI: 10.24198/pjd.vol32no3.27472

Submission: May 20, 2020; Accepted: Nov 14, 2020; Published online: Nov 30, 2020

\section{INTRODUCTION}

Bronchial asthma is a serious public health problem in almost all countries, including Indonesia. ${ }^{1,2}$ Based on Riskesdas 2018, asthma prevalence at all ages in Indonesian people is $2.4 \% .^{1,3,4}$ Bronchial asthma is a chronic disease characterizes with inflamed airway, various degrees of airway obstruction, mucous hypersecretion, and airway hyperresponsiveness. ${ }^{5}$ Inhalation therapy has become the first choice and often use for administering drug in asthma disease treatment. Comparing to other administration routes, inhalation therapy makes the inhaled drugs reach the airway directly. It decreases systemic side effect that is often caused by systemic administration route. ${ }^{6,7,8}$ Inhaler is used for inhalation therapy, but many patients and health

"Corresponding author: Audrey Amber Vieri, Department of Oral Medicine, Faculty of Dentistry Universitas Padjadjaran, Indonesia. Jalan Sekeloa Selatan I, Bandung, West Java, Indonesia, 40132. Phone: +6287776954820; Email: audrey16002@ mail.unpad.ac.id 
workers have limited knowledge about technique and election of inhalers that influence drug deposit. Studies have shown that only a little of the total doses that reach the target organ, while the rest are deposited in the mouth. It causes side effects on the oral mucosa and makes oral mucosa more susceptible to damage or infection that manifested as oral lesion. 5,9,10,11,12

Many studies have proved that oral lesions are commonly found in bronchial asthma patients using inhalation drugs. This reflects the lack of knowledge and awareness of health workers and patients about inhalation drug adverse effects, especially corticosteroid and beta 2 agonist as the mainstay therapy for asthma patients. In previous study conducted in Iran, 100 asthmatic patients that mostly use corticosteroid inhaler and 100 healthy subjects were examined, the most oral lesions found in asthma patients were candidiasis, fissured tongue, and geographic tongue, while fissured tongue is the most oral lesion found in healthy subjects. ${ }^{13}$

In another study, 250 adult asthma and COPD patients in India with different duration and doses of corticosteroid and beta 2 agonist inhalation drugs usage were examined, ulceration found in subjects that use inhaler for less than 1 year, while in subjects that use inhaler for 1 year or more there are other oral lesions found such as candidiasis, pigmentation, and depapillation of tongue surface, however no statistical significance was observed with the dosage and lesions. ${ }^{14}$

Although many studies have been done, based on authors' search this study has not been done in Indonesia, as asthma is also a serious health problem in Indonesia, Indonesian asthma patients are at high risk of oral because of the use of inhalation drugs. The purpose of this study was to describe the clinical appearance and percentage of the oral lesion in bronchial asthma patients using inhalation drugs that can increase the knowledge about the oral lesions appearance and increases the awareness against the risk of oral lesions in bronchial asthma patients using inhalation drug.

\section{METHODS}

This study used a descriptive observational design with cross-sectional study. The population of this study was based on a central limit theorem that included 30 bronchial asthma patients who received inhalation therapy, such as corticosteroid and beta 2 agonist. This study was done in 2 months at Balai Besar Kesehatan Paru Masyarakat in Bandung city. Two months' period was selected based on discussion with staff in research place to reach the number of subjects.

The inclusion in this study was patient that received inhalation therapy for at least one year, while the exclusions in this study were patients that suffering from other systemic diseases such as autoimmune diseases, hematologic diseases such as anemia, leukemia, and thrombocytopenia, endrocrine disease such as diabetes mellitus, using a denture and orthodontic appliance that may have oral lesion from the systemic condition and the appliance.

The selection of the samples was achieved by cooperation with the doctors and nurses at the research place to make sure that every sample was suitable to the criteria.Subjects were asked some questions about their identity and general condition. Subjects received information about this study and made an agreement through informed consent.

Subjects were instructed to gargle with freshwater and then their mouths were observed directly with the naked eye or with help by mouth mirror. All lesions found in oral mucosa were noted and photos of the lesions were taken. All founded lesions were grouped based on its clinical appearance and the calculation of the lesion percentage was divided by 30 (total subjects), this results in percentages of oral lesions based on its clinical appearance in 30 subjects. Ethical approval: 1390/UN6.KEP/EC/2019 by the Health Research Ethics Committee of Padjadjaran University.

\section{RESULTS}

Table 1 presents data and subject characteristics based on gender and age. Based on subject's gender, most subjects are females (83\%), while males only $17 \%$. Based on the age, subject aged $17-25$ years old is only 1 subject (3\%) that consists of 1 female, 26-45 years old is 5 subjects (17\%) that consist of 5 females, 46-65 years old is 20 subjects $(67 \%)$ that consists of 16 females and 4 
males, and subjects that older than 65 years old is 4 subjects $(13 \%)$ that consists of 3 females and 1 males. This result shows that all of the subjects have passed the puberty phase and are dominated by females.

Table 1. Characteristics of bronchial asthma patients

\begin{tabular}{ccccc}
\hline \multirow{2}{*}{ Age } & \multicolumn{2}{c}{ Gender } & & n \\
\cline { 2 - 3 } & Female & Male & & $\%$ \\
\hline $17-25$ & 1 & - & 1 & 3 \\
$26-45$ & 5 & - & 5 & 17 \\
$46-65$ & 16 & 4 & 20 & 67 \\
$>65$ & 3 & 1 & 4 & 13 \\
$n$ & 25 & 5 & & \\
\hline
\end{tabular}

Table 2 presents data of oral mucosal lesions found and its percentage from 30 subjects (100\%). Oral lesion that have the highest percentage is plaque found at 22 subjects $(73.3 \%)$, followed by fissure found at 11 subjects (36.7\%), atrophy found at 9 subjects (30\%), pigmentation found at 1 subject (3.3\%), bullae found at 1 subject (3.3\%), and petechiae found at 1 subject (3.3\%).

Table 2. Distribution frequency of oral lesions in bronchial asthma patients

\begin{tabular}{ccc}
\hline Oral Mucosal Lesion & $\mathrm{n}$ & $\%$ \\
\hline Plaque & 22 & 73.3 \\
Fissure & 11 & 36.7 \\
Atrophy & 9 & 30 \\
Pigmentation & 1 & 3.3 \\
Bullae & 1 & 3.3 \\
Petechiae & 1 & 3.3 \\
\hline
\end{tabular}

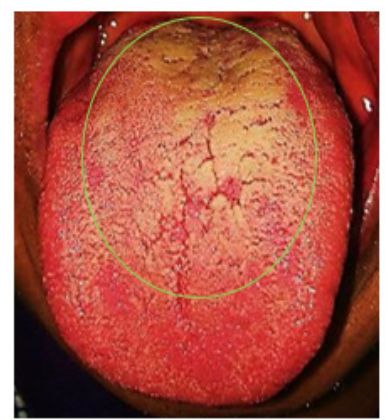

Figure 1. Plaque appears on $2 / 3$ posterior dorsal of the tongue, has white-yellowish color, irregular border, and raised appearance resembling milk curds or cottage cheese (green circle), found in male patient, 70 years old, use corticosteroid and beta 2 agonist inhaler for 2 years (Personal documentation)

All of the figures presented in this article are personal documentation during the research.
Each figure represents each type of lesions found during the research. Plaque found in this study is shown in Figure 1, atrophy in Figure 2, geographic tongue found in Figure 3, fissured tongue in Figure 4. Other lesions found in this study were pigmentation, bullae, and petechiae, which are shown in Figure 5, Figure 6, and Figure 7 respectively.

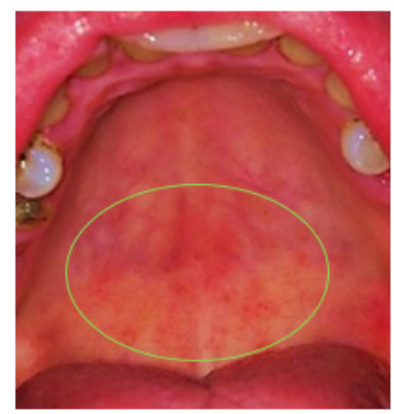

Figure 2. Atrophy appears as a redness area, located on the posterior of palatal mucosa, and it has diffuse appearance (green circle), found in female patient, 59 years old, use corticosteroid-beta 2 agonist inhaler for 5 years (Personal documentation)

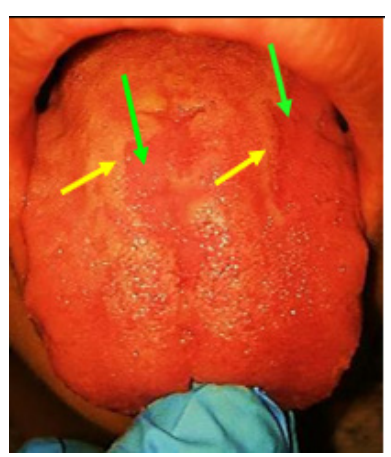

Figure 3. Atrophic appears as two redness area (redness island) located on the middle and left aspect of dorsal tongue mucosa, smooth surface (green arrow) surrounded by raised leading and folded edges in white-yellowish color as plaque (yellow arrow), found in female patient, 26 years old, use corticosteroid-beta 2 agonist inhaler for one year (personal documentation)

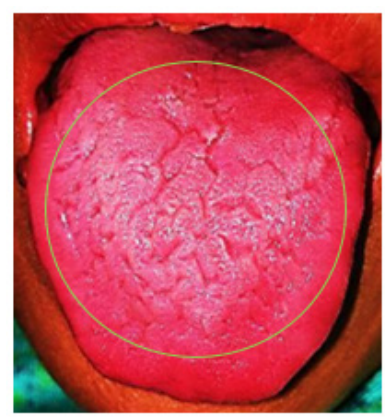

Figure 4. Fissure tongue appears as multiple fissure/ grooves located on $2 / 3$ anterior dorsal of the tongue that make the tongue surface looks separated into small islands (green circle), found in female patient, 53 years old, use corticosteroid-beta 2 agonist inhaler for more than 10 years (personal documentation) 


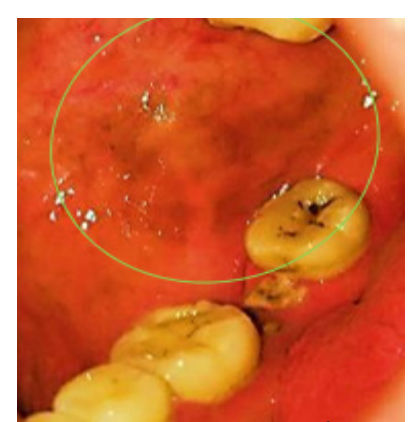

Figure 5. Pigmentation, appears on the posterior buccal mucosa (green circle), has diffuse appearance, dark-brown color, the size is about $3 \mathrm{~cm}$, found in female, 54 years old, use corticosteroid-beta 2 agonist inhaler for 2.5 years (personal documentation)

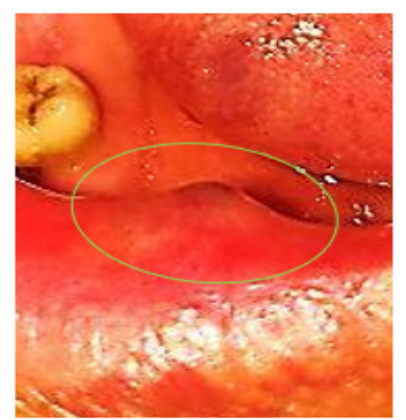

Figure 6. Bullae has dark red-purplish color, prominent, and the size is approximately more than $1 \mathrm{~cm}$, found in male, 65 years old, use corticosteroid-beta 2 agonist inhaler for $\mathbf{1 . 5}$ years (personal documentation)

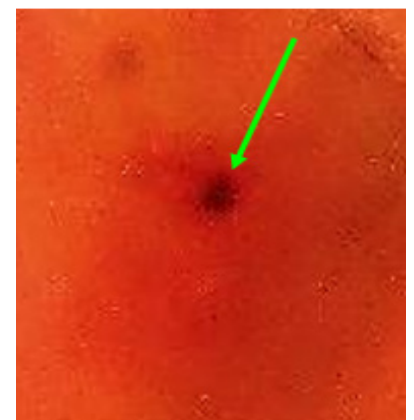

Figure 7. Petechiae has a dark red color, has a round shape, appears in a small size (about $1-2 \mathrm{~mm}$ ) on oral mucosa, found in female, 72 years old, use corticosteroidbeta 2 agonist inhaler for 9 years (personal documentation)

Table 3 presents data of oral lesions found based on the duration of inhalation therapy. Plaque, atrophy, fissure, bullae, pigmentation, and petechiae were found in subjects that received therapy for 1-10 years. Plaque, atrophy, and fissure were found in subjects that received therapy for more than 10 years.

Table 3. Oral lesion based on therapy duration

\begin{tabular}{cc}
\hline Duration of therapy (year) & $\begin{array}{c}\text { Type of oral lesions } \\
\text { Plaque, atrophy, fissure, } \\
\text { pigmentation, bullae, } \\
\text { petechiae } \\
1-10\end{array}$ \\
$>10$ & Plaque, atrophy, fissure \\
\hline
\end{tabular}

\section{DISCUSSION}

Based on Table 1, most of the subjects are females $(83 \%)$, while males only $17 \%$. The age of all subjects have passed the puberty phase, it can be called that subjects in this study are dominated with the post-puberty females. This is supported by Fuseini and Newcomb ${ }^{15}$ study, that asthma symptoms increase in girls starting at puberty compared to males. The transition from childhood to adulthood is characterized by asthma worsening in females and asthma improvement in males. ${ }^{16}$

Hormonal changes play a role in this, estrogen hormone increases in females at puberty that elevates eosinophils and mast cells degranulation which increase airway inflammation responses, while testosterone hormone increase in males and decreases airway inflammation responses. Zein and Erzurum ${ }^{16}$, present the results of some studies that also show asthma prevalence in females is higher than males after puberty. Increases of progesterone impact the mucociliary clearance that induces asthma symptoms, also asthma prevalence in females increases linearly with the number of births. ${ }^{16}$ This explains why the samples are dominated by females.

Pathogenesis of asthma patients involve 2 phases. The early phase is initiated by IgE antibodies that bind to mast cells and basophils. When certain triggers get inhaled, mast cells release inflammatory mediators that cause smooth muscle to contract and tighten the airway. Within the next several hours, the late phase occurs, eosinophils, basophils, neutrophils, helper, and memory $T$ cells localize to the lung and perform bronchoconstriction and inflammation. ${ }^{17}$ This condition can be relieved and controlled by inhalation drugs such as corticosteroid and beta 2 agonist, but the deposited of the drugs in oral cavity is closely linked with some adverse effects explained by mechanism in the next paragraph.

Inhalation drugs for asthma patient treatment in this study contain corticosteroid and beta 2 agonist. Inhaled corticosteroid (ICS) uses as a controller by resist and reduces inflammation cells and inflammation mediators, while beta 2 agonist uses as a reliever by bonding to beta 2 receptors at bronchial smooth muscle and causing relaxation. Secretion of saliva by salivary glands either major or minor can be impaired by the 
local deposit of corticosteroid and beta 2 agonist in the mouth. Salivary secretion involves acinar and ductal cells, channels, and transporters such as the release of $\mathrm{Ca}^{2+}$ from endoplasmic reticulum (ER) in salivary glands cells.

This leads to increases in intracellular calcium concentration. Increases $\mathrm{Ca}^{2+}$ induces $\mathrm{Cl}^{-}$ movement through the channel. The accumulation of $\mathrm{Cl}^{-}$in the lumen induces water movement for saliva secretion. Corticosteroid affects the expression or function of channels and transporters such as $\mathrm{Ca}^{2+}$ signaling that is important in the saliva secretion mechanism resulting in decreases of saliva secretion. ${ }^{18}$

Corticosteroid also reduces the expression of the enzyme phospholipase $A_{2}$, lead to decreases of arachidonic acid and the transcription of inflammation mediators that is important in the mucosal defense system, this makes oral mucosa more susceptible to infection. ${ }^{19}$ Beta 2 receptors also present at salivary glands cells, considering that beta 2 agonist acts by bonded to the receptors and this binds increases cyclic adenosine monophosphate (CAMP) and activation of protein kinase $\mathrm{A}$ (PKA) that can act by interfering $\mathrm{Ca}^{2+}$ that is important in saliva secretion. ${ }^{20}$

It can be concluded that the use of these inhalation drugs result in hyposalivation and may make the subject experiences subjective feeling such as xerostomia. Reduces of saliva that has important roles such as buffering, lubrication, antimicrobial, and other protective roles in maintaining the health of oral mucosa and reduces of oral mucosal defense system can lead oral mucosa more susceptible to infection such as candidiasis in plaque or atrophy form and trauma that can results pigmentation, bullae, and petechiae, reduces of saliva also make the fissure appearance on the tongue is more obvious. ${ }^{21}$

Based on table 2, oral lesions that are clinically found in this study are plaque, atrophy, fissure, pigmentation, bullae, and petechiae. The table presents that plaque is the most oral lesion was found (73.3\%), followed by fissure and atrophy, while pigmentation, bullae, and petechiae are the least oral lesions were found. Gaphanchi et $\mathrm{al}^{13}$ in his study also presents that the most prevalent oral lesions in asthmatics group are fissure, plaque, and atrophic lesions as fissured tongue, geographic tongue, and candidiasis. Ayinampudi et $\mathrm{l}^{14}$ also found in his study that candidiasis on the tongue is commonly found in asthma patients using inhalers.

Plaque (Figure 1 ) in this study are clinically diagnosed as pseudomembranous candidiasis and coated tongue. Pseudomembranous candidiasis and coated tongue difference can be achieved by further confirmation or examination, as scraping off the lesion, when the pseudomembranous candidiasis scrape off, it leaves an underlying erythematous area, while the coated tongue doesn't. 22

The use of Inhaled Corticosteroids (ICS) increases the risk of oral candidiasis due to the local immunosuppressant and lack of cleansing function by saliva that provides substances for fungal growth. ${ }^{23}$ The use of Dry Powder Inhaler that contains sugar also increases the growth of Candida. 14,22 Candida forms accumulation of desquamated epithelium, candida hyphae, fibrin, and necrotic tissue which provides a clinical appearance as raised white-yellowish plaque. ${ }^{24}$ Coated tongue occurs as a cleansing function of saliva decrease. ${ }^{25}$

Atrophy (Figure 2) in this study are clinically diagnosed as erythematous candidiasis and geographic tongue. Geographic tongue looks like redness island as the atrophic area (Figure 3, green arrow) around the raised white-yellowish plaque (Figure 3, yellow arrow) at the tongue resembles a map. ${ }^{22}$ The etiology and pathogenesis of geographic tongue remains unknown but several studies have shown a link between asthma and geographic tongue. Nakamura et al. ${ }^{24}$ in his study stated that Candida is associated with atrophic lesion. Lesan et al. ${ }^{26}$ stated that geographic tongue incidence in asthmatic patients is 4.2 times higher compared to the control group.

Fissure at the dorsal tongue surface (Figure 4) is a normal variation, but it can be a sign of dry mouth. Gaphanchi et al. ${ }^{13}$ present data that fissured tongue is commonly found in asthmatic patients. Hyposalivation condition causes the fissures to become a place of microbes and debris accumulation that give rise to inflammation and make the appearance of fissure more obvious. ${ }^{27}$

Pigmentation in this study is located in the posterior buccal mucosa and has a diffuse dark brown appearance. Bakhtiari et al. ${ }^{28}$ stated drugs can induce pigmentation lesions (Figure 5) but 
the exact mechanism remains unclear. The use of drugs that cause hyposalivation can be linked to saliva function as a barrier of irritations that can induce pigmentation. ${ }^{29}$

Bullae lesions in this study are clinically diagnosed as angina bullosa haemorrhagica ( $A B H)$. $A B H$ is a subepithelial blister that is painless, tense, dark red, and blood-filled in the oral mucosa (Figure 6).

Trauma causes damage to epithelialconnective tissue joints that cause hemorrhage and form bullae. Ruiz et al. ${ }^{30}$ stated that oral mucosa angina bullosa haemorrhagica (ABH) etiology remains obscure, but the occurrences has also been linked to the use of inhaled steroids. Qian Ye et al. ${ }^{31}$ stated that asthmatic patients using inhaled steroid experiences skin thinning. The mucosa that has the same condition is susceptible to trauma and forms bullae or petechiae lesion (Figure 7).

Table 3 shows oral lesion types that are found regarding the duration of inhaler usage. Plaque, atrophy, fissure, bullae, pigmentation, and petechiae were found in 1-10 years of therapy. Plaque, atrophy, and fissure were found In more than 10 years of therapy. Ayinampudi et $\mathrm{al}^{14}$ shows different results, ulcerations were found in 1-10 years of therapy, while other lesions that are not mentioned, candidiasis, depapillation, ulceration, and pigmentation were found in more than 10 years of therapy.

The similarity of the present study results and previous studies due to the subjects in this study also receive the same inhalation drug that contain corticosteroid or beta 2 agonists. Thus patients experience the same impacts, such as immune system and saliva secretion decrease. The impacts increase the potential of developing similar oral lesions. Therefore, the asthmatic patients with inhalation therapy are at higher risk of oral lesions. However, there's differences of oral lesion types found regarding the duration of inhaler usage in this study and the previous study. There are limitations of this study, such as the limits of subjects included in this study, also this study doesn't have a control group to differentiate the conditions between the healthy subjects and asthma subjects. Moreover, the determination of the lesions is only based on clinical appearance without any further examination.

\section{CONCLUSION}

Plaque, fissure, atrophy, pigmentation, bullae, and petechiae are oral lesions that are clinically found in bronchial asthma patients using inhalation drugs.

\section{REFERENCES}

1. Ministry of Health of the Republic of Indonesia. Indonesia Health Profile 2012. Jakarta: Ministry of Health of the Republic of Indonesia; 2013. p. 1-8.

2. Nalina N, Chandra MRS, Umashankar. Assessment of quality of life in bronchial asthma patients. Int J Med Public Health. 2015; 5(1): 93-7. DOI: $10.4103 / 2230-8598.151270$

3. National Institute of Health Research and Development (NIHRD). Indonesia Basic Health Research (RISKESDAS) 2017-2018. Jakarta: Ministry of Health of the Republic of Indonesia; 2018. p. 45-50.

4. Jones GW. The 2010-2035 Indonesian Population Projection - Understanding the Causes, Consequences and Policy Options for Population and Development. Jakarta: UNFPA Indonesia; 2013. p. 24

5. Keles S, Yilmaz NA. Asthma and its impacts on oral health. Meandros Med Dent J. 2016; 17(1): 35-8. DOI: 10.4274/meandros.2569

6. Godara N, Godara R, Khullar M. Impact of inhalation therapy on oral health. Lung India. 2011; 28(4): 272-5. DOI: 10.4103/09702113.85689

7. Borghardt JM, Kloft C, Sharma A. Inhaled therapy in respiratory disease: The complex interplay of pulmonary kinetic processes. Can Respir J. 2018; 2018: 1-11. DOI: 10.1155/2018/2732017

8. Correll PK, Poulos LM, Ampon R, Reddel HK, Marks GB. Respiratory Medication Use in Australia 2003-2013: Treatment of Asthma and COPD. Canberra: Australian Institute of Health and Welfare; 2015. p. 64.

9. Bozejac BV, Stojšin I, Đurić M, Zvezdin B, Brkanić T, Budišin E, et al. Impact of inhalation therapy on the incidence of carious lesions in patients with asthma and COPD. J Appl Oral Sci. 2017; 25(5): 506-14. DOI: 10.1590/16787757-2016-0147 
10. Scichilone N. Asthma control: The right inhaler for the right patient. Adv Ther. 2015; 32(4): 285-92. DOI: 10.1007/s12325-015-0201-9

11. AbdulameerSA. Knowledgeand pharmaceutical care practice regarding inhaled therapy among registered and unregistered pharmacists: An urgent need for a patient-oriented health care educational program in Iraq. Int J Chron Obstruct Pulmon Dis. 2018;13: 879-88. DOI: 10.2147/COPD.S157403

12. Bjermer L. The importance of continuity in inhaler device choice for asthma and chronic obstructive pulmonary disease. Respiration. 2014; 88(4): 346-52. DOI: 10.1159/000363771

13. Ghapanchi J, Rezazadeh F, Kamali F, Rezaee M, Ghodrati M, Amanpour S. Oral manifestations of asthmatic patients. J Pak Med Assoc. 2015; 65(11): 1226-7.

14. Ayinampudi BK, Gannepalli A, Pacha VB, Kumar JV, Khaled S, Naveed MA. Association between oral manifestations and inhaler use in asthmatic and chronic obstructive pulmonary disease patients. J Dr NTR Univ Health Sci. 2016; 5(1): 17-23. DOI: 10.4103/2277$\underline{8632.178950}$

15. Fuseini $H$, Newcomb DC. Mechanisms driving gender differences in asthma. Curr Allergy Asthma Rep. 2017; 17(3): 1-15. DOI: 10.1007/ s11882-017-0686-1

16. Zein JG, Erzurum SC. Asthma is different in women. Curr Allergy Asthma Rep. 2015; 15(6): 28. DOI: $10.1007 / \mathrm{s} 11882-015-0528-y$

17. Sinyor B, Perez LC. Pathophysiology of Asthma. Treasure Island: StatPearls Publishing; 2020. p. 1-5.

18. Kusuda Y, Kondo Y, Miyagi Y, Munemasa T, Hori $\mathrm{Y}$, Aonuma F, et al. Long-term dexamethasone treatment diminishes store-operated $\mathrm{Ca}+$ entry in salivary acinar cells. Int J Oral Sci. 2019; 11: 1-8. DOI: 10.1038/s41368-018-0031$\underline{0}$

19. Janahi IA, Rehman A, Baloch NUA. Corticosteroids and Their Use in Respiratory Disorders. In: Al-Kaf AG (ed). Corticosteroids. London: InTech Open; 2018. p. 47-57.

20. Hsu E, Bajaj T. Beta 2 Agonists Treasure Island: StatPearls Publishing; 2020. p. 1-9.

21. Khalifa MAAA, Abouelkheir HM, Khodiar SEF, Mohamed GAM. Salivary composition and dental caries among children controlled asthmatics.
Egypt J Chest Dis Tuberc. 2014; 63(4): 777-88.

DOI: 10.1016/j.ejcdt.2014.05.003

22. Patil S, Rao RS, Majumdar B, Anil S. Clinical appearance of oral Candida infection and therapeutic strategies. Front Microbiol. 2015; 6: 1-10. DOI: 10.3389/fmicb.2015.01391

23. Ming SWY, Haughney J, Ryan D, Patel S, Ochel M, D'Alcontres MS, et al. Comparison of adverse events associated with different spacers used with non-extrafine beclometasone dipropionate for asthma. Prim Care Resp Med. 2019; 29(1): 1-8. DOI: 10.1038/s41533-0190115-0

24. Nakamura S, Okamoto MR, Yamamoto K, Tsurumoto A, Yoshino $\mathrm{Y}$, Iwabuchi $\mathrm{H}$, et al. The candida species that are important for the development of atrophic glossitis in xerostomia patients. BMC Oral Health. 2017; 17(1): 1-8. DOI: 10.1186/s12903-017-0449-3

25. Nurdiana, Mardia IS. Relationship between glycemic control and coated tongue in type 2 diabetes mellitus patients with xerostomia. Pesqui Bras Odontopediatria Clin Integr. 2020; 13: 1-8. DOI: 10.4034/pboci.2019.191.126

26. Lesan S, Goudarzi N, Heidarnazhad $H$, Hassan GM. Comparison of the prevalence of geographic tongue in asthmatic patients and healthy subjects in Masih Daneshvari Hospital in 2014. J Res Dent Maxillofac Sci. 2017; 2(1): 1-5. DOI: 10.29252 /jrdms.2.1.1

27. Sudarshan R, Vijayabala GS, Samata Y, Ravikiran A. Newer classification system for fissured tongue: An epidemiological approach. J Trop Med. 2015; 2015: 1-4. DOI: 10.1155/2015/262079

28. Bakhtiari S, Sehatpour M, Mortazavi H, Bakhshi M. Orofacial manifestations of adverse drug reactions: A review study. Clujul Med. 2018; 91(1): 27-36. DOI: $10.15386 /$ cjmed-748

29. Alawi F. Pigmented lesions of the oral cavity. An update. Dent Clin North Am. 2013; 57(4): 699-710. DOI: 10.1016/j.cden.2013.07.006

30. Beguerie JR, Gonzalez S. Angina bullosa hemorrhagica: Report of 11 cases. Dermatol Reports. 2014; 6(1): 5-7. DOI: 10.4081/ dr.2014.5282

31. Ye Q, He XO, D'Urzo A. A review on the safety and efficacy of inhaled corticosteroids in the management of asthma. Pulm Ther. 2017; 3: 1-18. DOI: $10.1007 / \mathrm{s} 41030-017-0043-5$ 